\title{
Secreting Pituitary Adenomas
}

The following eight papers have been assembled in this issue of the Canadian Journal of Neurological Sciences as a tribute of former pupils and friends of Dr. Jules Hardy, O.C., FRCS(C), Professor of Neurosurgery at the University of Montreal to mark the 25th anniversary of his introduction of the transsphenoidal pituitary microsurgery in 1962. Dr. Hardy's pioneering work has made Montreal a major referral and teaching center for pituitary and parasellar tumor surgery.

The original contributions to neurosurgery that are universally credited to Dr. Hardy are: - the introduction of the microscope and combined radiofluoroscopy, as well as specially designed microinstruments in transsphenoidal microsurgery of the pituitary, which have become the standard technique throughout the world; - the distinction and preservation of the still functional normal pituitary tissue allowing maintenance or re-establishment of the pituitary function after tumor surgery; - the recognition and development of the concept of micro adenomas of the pituitary, allowing innumerable infertile women with small prolactinomas to become pregnant, and establishing definitely ACTH-producing microadenomas as the main etiologic factor in Cushing's disease. 